\title{
Do dyslexia and stuttering share a processing deficit?
}

Mahmoud M. Elsherif $\mathrm{MSc}^{1 *}$, Linda R. Wheeldon $\mathrm{PhD}^{1,2}$ and Steven Frisson $\mathrm{PhD}^{1}$

${ }^{1}$ Department of Psychology, University of Birmingham, Birmingham, UK, B15 2TT

2 Department of Foreign Languages and Translation, University of Agder, 4604 Kristiansand, Norway,

${ }^{*}$ corresponding author

Email: mahmoud.medhat.elsherif@gmail.com

OrcidProfile: Mahmoud Elsherif \#0000-0002-0540-3998

\section{Highlights}

- Dyslexia and stuttering co-occur far more often than expected.

- $\quad$ Both populations show a similar degree of phonological difficulty.

- $\quad$ There might be a common underlying deficit between both conditions. 


\begin{abstract}
This study assessed the prevalence of childhood stuttering in adults with dyslexia (AWD) and the prevalence of dyslexia in adults who stutter (AWS). In addition, the linguistic profiles of 50 AWD, 30 AWS and 84 neurotypical adults were measured. We found that 17 out of 50 AWD (34\%) reported stuttering during childhood compared to $1 \%$ of the neurotypical population. This was moderated by the severity of dyslexia: People with mild dyslexia showed a lower prevalence rate $(15 \%)$ of childhood stuttering than those with severe dyslexia (47\%). In addition, we observed that $50 \%$ of the AWS $(n=30)$ fulfilled the diagnostic criteria of dyslexia, even though they had never been diagnosed as dyslexic. Compared to neurotypical adults, phonological working memory, awareness, and retrieval were similarly reduced in AWS and AWD. The findings supports the view that stuttering and dyslexia may share a phonological deficit.
\end{abstract}

Keywords: Dyslexia; stuttering; phonological processing; orthographic processing; semantics

\title{
Introduction
}

Dyslexia is a common neurodevelopmental condition, which manifests itself in the form of reading difficulties and occurs in $7-10 \%$ of the population (Peterson \& Pennington, 2012). Neuroimaging studies have shown structural and functional neural differences in dyslexics compared to neurotypical participants (Richlan, 2012; Richlan et al., 2009, 2011, 2013). People with dyslexia (PWD) show a dysfunction in the left hemisphere reading network, which includes the occipito-temporal, inferior frontal gyrus and inferior parietal regions (Richlan, 2012; Richlan et al., $2009,2011,2013)$. These regions are involved with phonological decoding and access to the phonological output lexicon and attentional mechanisms, respectively (Richlan, 2012; Richlan et al., 2009, 2011, 2013). While there are many different theories regarding the underlying causes of developmental dyslexia (see e.g. Reid, 2012, for an overview; Pennington et al., 2012), the dominant view is that PWD suffer from a deficit in phonological representation and/or processing, with individuals struggling to connect sounds to letters. This in turn, impairs the development of the 
orthographic lexicon, resulting in difficulties with reading (Bradley \& Bryant, 1983; Share, 1995; Snowling, 2000).

Stuttering is a neurodevelopmental disorder that results in difficulties with formulating motor plans for speech production. It is commonly assumed that stuttering occurs in about $5 \%$ of children and $1 \%$ of adults (e.g. Guitar, 2013). However, recent estimates (see Yairi \& Ambrose, 2013) suggest that prevalence of childhood stuttering might be somewhat higher (possibly around $8.5 \%$ ) and adult stuttering somewhat lower than previously thought (around .72\%; Craig et al., 2002). The stuttering brain is anatomically and functionally different from the typical brain (Chang et al., 2008; Chang et al., 2015; Chow \& Chang, 2017; Watkins et al., 2007), with differences mainly observed in the left hemisphere: the left Brodmann Area 47/12, left Heschl's gyrus, left motor cortex, left arcuate fasciculus, left inferior frontal gyrus, as well as bilateral temporal regions. These areas have been related to a host of different aspects of language processing in the neurotypical population, including phonological processing (Lavidor \& Ellis, 2003).

The etiology of stuttering remains unknown, though several of the influential models stress its multifactorial, dynamic nature (e.g. Smith \& Weber, 2017; Starkweather, 2002). According to these models, stuttering is principally a deficit of sensorimotor speech control rather than a language disorder per se (Smith \& Weber, 2017). However, its expression, severity, and likelihood of recovery have been associated with general and language-specific cognitive factors (see Bowers et al., 2018), as well as emotional factors. The current study, which focuses on phonological deficits, presents data consistent with the view that linguistic factors, such as phonology, play a crucial and possibly causal role in stuttering.

The relationship between different aspects of phonological processing and stuttering has been extensively researched in children, though the findings are equivocal across development, paradigms and studies (e.g. Ambrose et al., 2015; Bosshardt, 1993; Burger \& Wijnen, 1999; Byrd et al., 2007; Coalson \& Byrd, 2016; Hennessey et al., 2008; Smith et al., 2012; Vincent, 2017; Weber-Fox et al., 2004). For example, Byrd et al. (2007) found evidence of phonological encoding differences between 3- to 5-year old children who stutter (CWS) compared to children who did not stutter (CWNS), but Melnick et al. (2003) did not. Studies examining phonological memory, 
primarily using non-word repetition, tend to show lower task performance in CWS (Anderson \& Wagovich, 2010; Anderson et al., 2006; Hakim \& Bernstein Ratner, 2004; Oyoun et al., 2010; Pelczarski \& Yaruss, 2016; Spencer \& Weber-Fox, 2014 but see Bakhtiar et al., 2007; Smith et al., 2012). Children who stutter tend to be slower in phoneme monitoring tasks (Mahesh et al., 2018), though Sasisekaran and Byrd (2013) only observed a phoneme monitoring difficulty when cognitive demands increased. Children who stutter also tend to perform worse on specific phonological awareness tasks such as phoneme blending and phoneme elision (i.e. tasks that require manipulation of phonemes), while they score within normal limits in other phonological awareness tasks (e.g. determining which words share an initial or final phoneme with a target word; Pelczarski \& Yaruss, 2014). Together, evidence suggests that phonological deficits observed in CWS are exacerbated when cognitive demand is high.

In addition to cognitive demand, the likelihood of recovering from stuttering seems to affect CWS' performance on phonological tasks as well. For example, researchers from the Purdue Stuttering Project observed that reduced phonological skills contributed to the persistence of stuttering (see review by Walsh et al., 2018). For instance, in a longitudinal study, Spencer and Weber-Fox (2014) observed that the poorer the performance on articulatory skills and nonword repetition tests, the more likely stuttering persisted in that child. More evidence supporting a link between phonological deficits and the persistence of stuttering comes from brain studies such as Mohan et al. (2015; see also Gerwin \& Weber, 2020). They found a bi-hemispheric anterior onset rhyme effect (i.e. an expected neural index of early rhyme segmentation and rehearsal over the anterior neural regions) only in children who recovered from stuttering and the neurotypical group while children with a persistent stutter only showed this effect in the right hemisphere. However, some evidence suggests that while there might be a delay in phonological development in children who persist in stuttering, this does not necessarily indicate a phonological impairment. For example, in longitudinal study by Paden and colleagues (Paden et al., 2002 which was part of the same longitudinal study as Paden et al., 1999), initially found that phonological performance was worse in children who persisted in stuttering than those who eventually recovered from stuttering, but that this difference had largely disappeared a year later, and the two groups performed nearly identical 
two years later. The putative link between phonological processing and stuttering has not been researched as extensively in adults who stutter. When the task is relatively easy, such as picture naming tasks that test phonological priming, typically no group differences have been found (e.g. Hennessey et al., 2008; Vincent et al., 2012). In more demanding tasks, adults who stutter (AWS) tend to show poorer performance than neurotypical participants. These include tasks that assess phonological encoding (e.g. monitoring tasks, dual tasks, and tasks with increased phonological complexity; Bosshardt et al., 2002; Coalson \& Byrd, 2020; Howell \& Bernstein Ratner, 2018; Saisekaran \& de Nil, 2006; Sasiseakaran et al., 2006), phonological awareness (e.g. rhyme discrimination; Weber-Fox et al., 2004), and phonological working memory (at least for the more complex nonwords in a nonword repetition task; Byrd et al., 2015; Byrd et al. , 2012; Choopanian et al., 2019; Coalson \& Byrd, 2017). In a rhyme discrimination task, Weber-Fox et al. (2004) found that AWS performed similarly to fluent controls, except for the most difficult condition (orthographic but not phonological overlap, gown - own). In addition, AWS showed an increased activity in the right hemisphere while carrying out the task as a whole.

However, these studies need evaluation with regard to their generalisability. Firstly, the majority of these studies tested a relatively small number of PWS ${ }^{1}$. Secondly, the mixed findings concerning a phonological deficit in AWS may have been caused by a varying degree of print exposure. For instance, people with high print exposure have been found to name nonwords and to discriminate between words and nonwords more quickly and accurately than people with low print exposure (e.g. Chateau \& Jared, 2000). It has been argued that greater reading experience strengthens the relationship between orthographic and phonological representations, leading to faster activation of these representations (Mol \& Bus, 2011). Hence, in order to assess whether and to what extent phonological deficits in AWS can be ascribed to print exposure, it is necessary to include this measure. Finally, it has been observed that $30-40 \%$ of CWS have co-occurring speech, language, and non-speech-language disorders (e.g. Blood et al., 2003; Wolk et al., 1993).

\footnotetext{
${ }^{1}$ For example, the average number of participants in the 30 studies reviewed in Bowers et al. (2018) was $13.8(S D=6.6)$, for the subset of 17 AWS studies, the average was $12.9(S D=5.8)$. For the 22 studies reviewed in Ntourou et al.(2011), the average was $12.0(\mathrm{SD}=6.6)$.
} 
The phonological deficit may be therefore epiphenomenal to stuttering, and may result from an additional undiagnosed phonological or language disorder. However, most studies, excluding Smith et al. (2012), did not test for phonological disorders. Smith et al. (2012) found that CWS with co-occurring difficulties such as speech/sound disorders or language impairment performed worse on nonword repetition than CWS without additional disorders and the neurotypical group. CWS without any co-occurring impairment did not differ from neurotypical children in nonword repetition, suggesting that at least some of the observed group differences might have resulted from an additional language and/or phonological disorder (possibly including dyslexia), as opposed to stuttering per se.

While stuttering and dyslexia seem very different disorders at first sight, there are some intriguing commonalities. For example, both conditions have been shown to share similar genetic alleles (i.e. DRD2, GNPTAB and NAGPTA) that have been argued to be risk factors in the pathogenesis of the disorders (Chen et al., 2014, 2015). Both PWD and PWS show underactivation in the left inferior frontal gyrus and the left arcuate fasciculus (Chang et al., 2008; Chang et al., 2015; Choo \& Chang, 2017; Richlan, 2012; Richlan et al., 2009, 2011, 2013; Rimrodt et al., 2010; see review by Vandermosten et al., 2012). Both disorders show a large male bias (2:1 ratio for PWD and 3.7:1 ratio for PWS, Nogueira et al., 2015; Vlachos et al., 2013), and both PWD and PWS perform worse than neurotypical participants on diadochokinetic tasks (i.e. repeating /pa/ at least 15 times), indicating difficulties with motor control during speech production (Malek et al., 2013; see review by Snowling \& Melby-Lervag, 2016, for speech production deficits in PWD). In addition, as the review above indicates, phonological processing (e.g. phonological awareness, phonological working memory, and phonological retrieval) might be impaired in both disorders. However, while this is clear and generally accepted for PWD (see review by Melby-Lervag et al., 2012), the current evidence for AWS is more ambiguous. In fact, in some large-scale surveys, dyslexia, or more generally, difficulties with reading and writing, is sometimes mentioned as a concomitant factor in stuttering (Ajdacic-Gross et al., 2010, 2018; Ardila et al., 1994).

The present study measured the rate of childhood stuttering in adults with dyslexia (AWD) compared to a group of neurotypical participants, as well as the extent to which dyslexic processing 
characteristics can be observed in AWS. Our working hypothesis is that if dyslexia and stuttering are independent, then only about $8.5 \%$ of AWD will have stuttered as a child, and only about 7 $10 \%$ of AWS will be dyslexic, mirroring the prevalence rates in the general population. We will also compare AWD and AWS to each other in order to establish to what degree their phonological processing profiles match. If both groups show similar deficits in different aspects of phonological processes, then this would point to a similar phonological impairment. In addition, based on previous research, we expect that AWD will show spelling and possibly nuanced reading comprehension difficulties (see review by Bishop \& Snowling, 2004; Ransby \& Swanson, 2003), which we do not expect to find in AWS (e.g. Janssen et al., 1983; Williams et al., 1969).

\section{Methods}

\section{Participants.}

Originally, 91 monolingual British undergraduate students aged 18-22 ( $M=20.1 \pm 1.1$ years) from the University of Birmingham participated in the study in return for course credits or remuneration. These students were also involved in another unrelated study (see Elsherif et al., 2020a, 2020b). None of the neurotypical students self-reported dyslexia or stuttering, language impairment, or some other neurodevelopmental disorder or neurological insult. Six participants were excluded due to attrition and two due to the exclusion criteria to define dyslexia (see below). Fifty AWD aged 18-32 ( $M=20.7 \pm 2.7$ years; 27 males), recruited from local universities, and 30 AWS aged 18-48 years ( $M=29.5 \pm 8.91$ years; 22 males) participated for remuneration. Participants were matched as closely as possible in terms of age, educational level, bilingualism and handedness (see Table 1). Mirroring prevalence rates in the general population, there were more male participants in both the dyslexia and stuttering groups. All AWD provided a diagnostic report documenting a childhood history of dyslexia and had no history of attention deficit hyperactivity disorder or a current diagnosis of persistent stuttering using the DSM-V criteria, nor did they exhibit any overt signs of speech difficulties. In addition, none of the AWS had a history of attention deficit hyperactivity disorder or a current diagnosis of dyslexia using DSM-V criteria. The study was conducted in accordance with the British Psychological Society ethical guidelines and approved by 
the University's ethical committee. All participants had normal or corrected-to-normal vision and signed a consent form.

Education level was classified as A-levels (coded as 1), Bachelors (coded as 2), Masters (coded as 3) and PhD (coded as 4). The homogeneity of variance between groups was assessed with the Fligner-Killeen test. The dyslexia and neurotypical groups did not differ significantly from each other in terms of average education level $(t(77.27)=-1.86, p=.07)$, bilingualism $(t(132)=-1.86$, $p=.07)$, or age $(t(57.80)=-1.36, p=.18)$, but there were significantly more males $(t(67.10)=-5.90$, $p<.001)$ and left-handed individuals $(t(89.37)=-3.30, p=.001)$ in the dyslexia than in the neurotypical group. The stuttering and neurotypical groups did not differ significantly from each other in terms of average education level $(t(112)=-1.51, p=.13)$, bilingualism $(t(29)=-1.44, p=.16)$ or handedness $(t(112)=-0.32, p=.76)$, but there were significantly more males $(t(37.21)=-7.43, p<.001)$ and older individuals $(t(29.28)=-5.60, p<.001)$ in the stuttering group than in the neurotypical group. The stuttering and dyslexia groups did not differ significantly from each other in terms of gender $(t(80)=-$ 1.73, $p=.09)$, bilingualism $(t(78)=-0.52, p=.60)$, or average education level $(t(78)=0.08, p=.94)$ but the average age was higher in the stuttering than in the dyslexia group $(t(32.13)=-5.15, p<.001)$, and there were more left-handed individuals in the AWD compared to the AWS group $(t(75.85)=2.63, p=.01)$ (For a discussion of sinistrality in people with dyslexia, see Bishop, 1990; Eglinton \& Annett, 1994).

Table 1. The means and standard deviation for demographic variables for all diagnostic groups.

\begin{tabular}{lccc} 
& Neurotypical $(\mathbf{N}=\mathbf{8 4})$ & Dyslexic $(\mathbf{N}=50)$ & Stuttering (N = 30) \\
\cline { 2 - 4 } & Mean (SD) (range) & Mean (SD) (range) & Mean (SD) (range) \\
Age (year) & $20.18(1.03)(18-23)$ & $20.72(2.7)(18-32)$ & $29.47(8.91)(18-44)$ \\
Education (1-4) & $1.04(0.23)(1-3)$ & $1.14(0.35)(1-2)$ & $1.13(0.43)(1-3)$ \\
Gender (\%female) & $91.7(0.28)$ & $46(0.50)$ & $27(0.42)$ \\
Handedness (\%Right) & $89(0.41)$ & $62(0.49)$ & $87(0.33)$ \\
Bilingualism (\%Bilingual) & $0(0)$ & $4(0.20)$ & $7(0.25)$
\end{tabular}




\section{Standardized tests}

Demographic questionnaire. This questionnaire collected background information on participants, including age, gender and handedness.

\section{Language measures.}

Phonological processing. The following subtests from the Comprehensive Test of Phonological Processing (CTOPP; Wagner et al., 1999) were used to measure phonological processing: phoneme elision, rapid letter naming $(R L N)$, memory for digits, non-word repetition and phoneme reversal. In the phoneme elision task, the participant had to remove a given phoneme from a word and to say the resulting word (e.g. mat without $/ \mathrm{m} /$ is at). $\mathrm{ln}$ the non-word repetition task, the participant heard nonwords and had to repeat them back to the experimenter. In the phoneme reversal task, the participant heard a phoneme or nonword and had to reverse the phoneme or nonword to form a real word (e.g. na forms an). In all three tasks there were 18 items and the number of correct answers was recorded. In the memory for digits test, the participant heard digits and had to repeat them back to the experimenter. There were 21 items and the number of correct answers was recorded. In the RLN subtest, the participant had to name 36 printed letters as quickly as possible, and the time taken to name all letters was recorded. There was no time limit imposed in any of these five tasks.

Reading Fluency. Two subtests from the Test of Word Reading Efficiency (TOWRE, Torgesen et al., 1999) were used to assess reading fluency: sight word reading (TOWRE-W) and nonword reading (TOWRE-P, which measures phonemic decoding). In addition, irregular word reading was assessed by the Test of Irregular Word Reading Efficiency (TIWRE; Reynolds \& Kamphaus, 2007). The TOWRE-W required the participant to read out loud regular words (i.e. words that conform to English spelling rules; e.g. strange), within a set time limit. The maximum number that could be achieved is 108 words. The TOWRE-P was identical but the stimuli were 66 pronounceable nonwords (i.e. made up words that conform to English spelling rules; e.g. tindor). Following guidelines, the neurotypical group and the AWD group were given 45 s to complete each task. However, we substantially increased the time limit for AWS from 45s to 3 minutes in order to reduce the external time pressure, which AWS can struggle with (Perkins et al., 1991). For scoring 
purposes, the number of responses up to the first $45 \mathrm{~s}$ were counted. Only one AWS participant showed signs of disfluency in these two tasks. However, removing their score did not alter the pattern of results. The TIWRE required participants to read 25 words with irregular spelling patterns (i.e. words where one or more elements do not conform to English spelling rules, e.g., great) with no time limit. Nonwords allow us to assess phonological decoding (i.e. grapheme-phoneme conversion), whereas irregular words measure access to orthographic representations (Bowey \& Rutherford, 2007; Cortese \& Simpson, 2000).

The Stuttering Severity Instrument, version 3 (SSI-3: Riley, 1994) was used as a standardized measure to determine stuttering severity in AWS. The SSI-3 required each AWS to provide a conversational speech sample and read a text passage aloud. For all participants, we video-recorded speech samples for 10 minutes and collected 500 -syllable long speech samples to compute severity estimates. The frequency of stuttering events in conversational speech and reading samples, and the duration of stuttering events and the frequency of behaviours peripheral to stuttering (i.e. physical concomitants) are combined in the SSI-3, providing a single score to indicate the severity of stuttering. None of the participants exhibited cluttering behaviours or had atypically high typical disfluencies. The average score on the SSI-3 across PWS was 21.9, which is classified as mild (range: 10-37; mild to severe stuttering).

Print exposure. Research has shown that amongst university students, higher print exposure results in more efficient orthographic and phonological processing (Chateau \& Jared, 2000). Hence, we included a print exposure measure to ascertain that differences in performance could not be attributed to differences in reading experience. This is especially important in dyslexia studies where differences in print exposure have been shown to confound cause and effect (Huetti et al., 2018). Print exposure was assessed with the Author Recognition Test (ART), adapted from Stanovich and West (1989), and the Title Recognition Test (TRT), adapted from Cunningham and Stanovich (1990). The ART is a checklist which requires participants to choose whether they are familiar with the name of an author by ticking their name. The ART checklist consists of 100 names (50 real author names and 50 foils). The TRT follows the same procedures as the ART, with participants ticking familiar book titles including plays, poetry and novels (TRT). The TRT checklist 
had 100 book titles (50 real and 50 foils). We modified the original tests to include current and classic authors, together with book titles from Amazon's top 100 authors, for a British audience. (A pre-test with 100 additional participants from the same population showed a normal distribution in their answers). There was no time limit for completing the checklists. For each participant, a score was calculated by subtracting the number of ticked foils (i.e. false alarms) from the number of correctly recognized authors (i.e. hits). The composite measure of print exposure is an average of author recognition test and title recognition test.

Receptive vocabulary. The British Picture Vocabulary Scale $2^{\text {nd }}$ edition (BPVS-II; Dunn et al., 1997) was used to measure the participants' receptive vocabulary. The participant heard a prerecorded word and was asked to select the corresponding picture from a choice of four, with no time limit. Each participant completed six vocabulary sets (Sets 9-14). E-prime (E-studio, E-prime 2.0) software was used to implement this task. The correct answers were recorded and totalled for each participant.

Expressive vocabulary. In the Expressive Vocabulary Test second edition (EVT-2, Williams, 2007), the participant was asked to name objects (e.g. astronaut) or to describe what a person was doing (e.g. singing) with reference to a picture, with no time limit. There were 109 items and the number of correct answers was recorded.

Reading comprehension. In the Gray Silent Reading Test (GSRT; Widerholt \& Blalock, 2000), each participant read six brief stories (Stories 4-9) silently. The stories increased in complexity. The participant had to answer five multiple choice questions per story with no time limit. E-prime software was used to implement this task. The number of correct answers was recorded.

Spelling. The spelling subtest was based on the British Ability Scale (Elliott et al., 1996). Twenty words were dictated to the participant, which they had to spell accurately, with no time limit. The number of correctly spelled words was recorded. We included a spelling measure as it is used as an additional measure to assess dyslexia (Hanley, 1997).

Manual Stroop task. This task required participants to indicate whether a font colour and a word (font: Arial, size: 34) were the same or not. For instance, if participants saw the word BLUE with the font colour blue (congruent), they had to press 'YES' with their dominant hand to indicate 
they were the same. If the font colour was red instead of blue (incongruent), they had to press the 'NO' button with their non-dominant hand to indicate they were different. This test allowed us to investigate the role of inhibitory control during word recognition. Each trial began with a fixation cross of $500 \mathrm{~ms}$ followed by the target, to which they had to respond within $2000 \mathrm{~ms}$. The present study used 25 incongruent trials and 75 congruent trials, forcing participants to maintain the goal of word naming rather than focusing primarily on the goal of colour naming (e.g. Stroop, 1935). Eprime (E-studio, E-prime 2.0) software was used to implement this task. Responses were recorded via a keyboard. For each participant, the average reaction time for the correct answers and the proportion correct were recorded. An inverse efficiency score (IES) was calculated (Bruyer \& Brysbaert, 2011; Townsend \& Ashby, 1978), which is an aggregated measure that combines speed and accuracy in one measure.

The equation is below:

$$
I E S=\frac{R T}{P C}
$$

IES is calculated by dividing reaction time (RT) by the proportion of correct responses (PC); smaller numbers indicate greater efficiency (Bruyer \& Brysbaert, 2011; Townsend \& Ashby, 1978).

Naming Stroop task. Participants saw a coloured word and had to name the font colour, not the word (font: Arial, size: 43; Stroop, 1935). For instance, participants saw the word BLUE with the font colour blue (congruent) and had to say BLUE. If the font colour was red instead of blue (incongruent), they had to say RED. The same procedure and scoring system were used as for the Manual Stroop task. Responses were recorded with a voice key.

Non-verbal intelligence measure. The Raven's Standard Matrices test assessed non-verbal intelligence (Raven, 1960). Participants were shown 60 patterns of increasing complexity and had to select which pieces completed each complex pattern. E-prime (E-studio, E-prime 2.0) software was used to implement this task. The number of correct answers was recorded and no time limit was set. 


\section{Procedure}

At the beginning of the study, participants were given a demographic questionnaire, which collected background information including age, gender, handedness, bilingual, education level, type of intervention (e.g. speech-language therapy), history of dyslexia and history of stuttering, length of intervention, family members with these conditions. A clear definition of stuttering (based on the definition provided by Guitar, 2013) was provided on the participant information sheet. If participants stated on the questionnaire that they had stuttered as a child, they were asked to verify this verbally and with evidence from their educational reports ${ }^{2}$. After filling out the questionnaire, participants completed a battery of tasks designed to test phonology (phonological working memory, phonological retrieval, and phonological awareness), vocabulary, reading comprehension, inhibitory control and reading fluency.

Data analyses. All analyses were two-sided and the $\alpha$ value used to indicate significance was .05. All data were analysed within the $R$ statistical programming environment, version 1.1.456 ( $R$ Core Team, 2016) The package 'tidyverse' version 1.1.1 (Wickham, 2017) was used for data processing. The package 'Isr' 0.5.0 (Navarro, 2015) was used to compute Cramer's $V$. The package 'effsize' 0.7.4 (Torchiano, 2017) was used to compute Cohen's $d$ and glass delta. The package 'DescTools' 0.99.30 (Signorell, 2019) was used to compute $G$ tests of independence. The data, R markdown scripts and materials for all experiments are available at the open science framework at https://osf.io/wzd6k/. None of the experiments were pre-registered. Prior to making any comparisons and to better understand the differences between AWS and AWD, we analysed the responses between groups for each standardised test with an independent $t$-test (see Table 3 for each population). In order to reduce the chance of finding a type I error, we used a Holm-Bonferroni correction to report the significance of tests that were not planned. Hence, all the tests excluding those that assessed phonological processing and reading fluency measures have the corrected $p$ value (See Tables 2 and 3).

2 One PWD participants stated that she stuttered as a child, though this was not listed in her educational report. We therefore placed her in the non-childhood stuttering group. 
Post-hoc power analyses. As there is currently no good evidence we could rely on to calculate expected effect sizes, we performed post-hoc power analyses on the $G$ test for the prevalence rates and independent $t$-test for group differences in terms of the composite scores (see below for calculations) using G*Power (Faul et al., 2009). The degrees of freedom, total sample size and effect size were set according to test-specific calculations in R and alpha was set at 05 . The power analyses described below indicate that the analyses within the PWS and PWD groups might be underpowered to confidently assess small effects. However, our main findings have medium-to-large effect sizes (.5 to .8), and, thus, do not suffer from a lack of power. In addition, a post-hoc power that was above 0.99 indicates that the effect size is large and highly replicable.

\section{Results}

\section{Prevalence of childhood stuttering in neurotypical and dyslexic participants.}

Our findings showed that among the 50 AWD, 17 ( 6 female) stuttered as a child (a rate of childhood stuttering of $34 \%$; $95 \% \mathrm{Cl}[20.7,47.3])$, which was significantly higher than the $1 \%(n=1 ; 1$ male; $95 \% \mathrm{Cl}[-1.14,3.52])$ who stuttered as a child among the 84 neurotypical participants $(G(1$, $\mathrm{N}=134)=30.78, p<.001, V=.44$, post-hoc power $>0.99$ ). In addition, we divided the AWD into subcategories of mild and severe dyslexia based on two standard deviations (2SD) below the mean of the neurotypical population in measures of phonological processing and reading fluency to assess whether the severity of dyslexia was affected the prevalence of childhood stuttering. We observed that among the 20 people with mild dyslexia, 3 ( 1 female) stuttered as a child (a childhood stuttering rate of $15 \%)$, which was significantly higher than the $1 \%$ who stuttered as a child among the 84 neurotypical participants $(G(1, N=104)=6.15, p=.01, V=.22$, post-hoc power $=0.61)$. For the 30 people with more severe dyslexia, 14 (5 female) stuttered as a child (a childhood stuttering rate of $47 \%$ ), which was significantly higher than the $1 \%$ who stuttered as a child among the 84 neurotypical participants $(G(1, N=114)=36.47, p<.001, V=.56$, post-hoc power $>0.99)$. In addition, we compared people with mild dyslexia to people with more severe dyslexia to assess whether childhood stuttering is more prevalent in the former than the latter. The relation between these variables was significant, $(G(1, N=50)=5.74, p=.02, V=.28$, post-hoc power $=0.51)$ : more people with severe dyslexia had stuttered during childhood than those with mild dyslexia. 


\section{Prevalence of dyslexia in adults who stutter.}

We classified AWS as dyslexic if they scored 2SD or below the mean of the neurotypical population in at least two measures of the following tests: CTOPP (assessing phonological processing), spelling and TOWRE (assessing sight word efficiency and phonemic decoding) (For a similar approach, see Hanley, 1997). We found that $50 \%$ of the 30 AWS ( $n=15 ; 3$ females; $95 \% \mathrm{CI}[31.8,68.2])$ matched the diagnostic criteria for dyslexia, which was significantly higher than the $2 \%$ among the neurotypical participants $(n=2 ; 0$ females; $95 \% \mathrm{CI}[-0.889,5.59]) \quad(G(1$, $\mathrm{N}=116)=36.08, p<.001, V=.56$ post-hoc power $>0.99$ ). It should be emphasized that none of the AWS had received a prior clinical diagnosis of dyslexia ${ }^{3}$.

\section{Differences between populations on standardised tests}

Behavioural check. To ensure our tests assessed articulatory processes, we correlated the relationship between stuttering severity and TOWRE-W, TOWRE-P, TIWRE, and RLN. The results showed that increased stuttering severity strongly correlated with decreased performance, except for the TIWRE. $(r=.79 ; p<.001$ for TOWRE-W; $r=.66 ; p<.001$ for TOWRE-P; $r=.45 ; p<.001$ for RLN; and $r=-0.15 ; p=.43$, for TIWRE).

Planned comparisons. Average results of each standardised test for each population are shown in Table 2. The inferential data with $t$-values, $p$-values, effect size and $95 \%$ confidence intervals are shown in Table 3. An overview of participants' performance on each individual task can be found in the supplementary materials. Planned contrasts revealed that AWD and AWS performed worse than the neurotypical population on the phonological processing and reading fluency measures. In addition, AWD performed worse than the neurotypical participants on

\footnotetext{
${ }^{3}$ We compared AWS who match the dyslexia profile with AWS who did not match the dyslexia profile, AWD that had stuttered during childhood and AWD that had not stuttered during childhood in terms of educational experience. This was done to assess whether this prevalence rate resulted from educational experience. We observed that there was no significant difference between AWS who matched the dyslexia profile and the neurotypical sample $(t(97)=0.57, p=.57)$, no significant difference between AWS who matched the dyslexia profile and AWS who did not match the dyslexia profile $(t(28)=1.74, p=.09)$, AWS who matched the dyslexia profile and AWD who had stuttered during childhood $(t(30)=0.94, p=.36)$ and AWS who matched the dyslexia profile and AWD who had not stuttered during childhood $(t(46)=1.79, p=.08)$. This indicates the prevalence rate was not the result of educational experience.
} 
phoneme reversal, but there was no difference between AWS and neurotypical participants on this task. AWD and AWS did not differ in performance on the following measures: tests of word (TOWRE-W) and nonword (TOWRE-P) reading, phoneme elision, memory for digits, nonword repetition, rapid letter naming $(R L N)$ and phoneme reversal. It might be interesting to highlight that for one of the principal measures in the fluency literature, nonword repetition, both AWD and AWS performed significantly worse than neurotypical controls, supporting previous research on both adults (AWD: Peter et al., 2018; Szenkovits \& Ramus, 2005; AWS: Byrd et al., 2012, 2015; Coalson \& Byrd, 2017) and children (CWD: de Bree et al., 2010; see review by Melby-Lervag \& Lervag, 2012; Roodenrys \& Stokes, 2001; CWS: Anderson et al., 2006; Anderson \& Wagovich, 2010; Pelczarski \& Yaruss, 2016). Interestingly, AWD and AWS performed remarkably similar on this task. See Figure 1 for a graphical representation of the main results ${ }^{4}$.

\footnotetext{
${ }^{4}$ Note that for the RLN graph, 1 outlier data point in the AWS group is not included for graphical reasons. Following recommendations in the open science framework (e.g. Price et al., 2015), this data point was included in the statistical analyses. However, excluding this data point from the analyses did not change the pattern of effects.
} 
Table 2. Behavioural profile of the neurotypical, dyslexia and stuttering population

\begin{tabular}{|c|c|c|c|}
\hline & Neurotypical $(\mathrm{N}=84)$ & Dyslexic ( $N=50)$ & Stuttering $(\mathrm{N}=30)$ \\
\hline & Mean (SD) & Mean (SD) & Mean (SD) \\
\hline Raven (/60) & $45.48(6.57)$ & $47.38(7.13)$ & $43.93(10.48)$ \\
\hline GSRT (/30) & $22.25(3.33)$ & $21.18(4.05)$ & $23.27(4.53)$ \\
\hline Print Exposure (/100) & $33.56(13.06)$ & $36.03(17.94)$ & $50.03(25.51)$ \\
\hline BPVS-2 & $42.74(7.27)$ & $42.40(7.78)$ & $39.60(9.93)$ \\
\hline EVT-2 & $71.86(8.01)$ & $72.95(10.36)$ & $77.80(13.93)$ \\
\hline TOWRE-W (/ 108) & $87.34(11.24)$ & $78.82(12.10)$ & $73.73(20.10)$ \\
\hline TOWRE-P (/60) & $57.88(5.56)$ & $49.3(7.15)$ & $51.87(10.94)$ \\
\hline TIWRE (/ 25) & $21.19(1.86)$ & $20.26(2.25)$ & $21.57(2.88)$ \\
\hline Spelling (/20) & $16.49(2.37)$ & $13.24(2.95)$ & $14.87(4.19)$ \\
\hline Manual Stroop (IES) & $134(97)$ & $157.79(75.60)$ & $144.34(103.35)$ \\
\hline Naming Stroop (IES) & $190(137)$ & $213.02(104.81)$ & $205.95(125.36)$ \\
\hline Phoneme elision (/20) & $16.67(2.38)$ & $15.32(3.04)$ & $15.07(3.60)$ \\
\hline Memory for digits (/21) & $16.65(2.14)$ & $14.34(2.04)$ & $15.33(3.08)$ \\
\hline Nonword repetition(/18) & $13.68(1.73)$ & $10.68(2.23)$ & $9.9(2.90)$ \\
\hline RLN (ms) & $26.27(4.79)$ & $32.59(9.42)$ & $42.13(52.94)$ \\
\hline Phoneme reversal (/18) & 11.43 (2.62) & $8.96(2.49)$ & $9.93(3.83)$ \\
\hline
\end{tabular}

Note. Total print exposure assessed by author and title recognition; inverse efficiency scores (IES); British Picture Vocabulary Scales $2^{\text {nd }}$ edition (BPVS-2); Expressive Picture Vocabulary Test $2^{\text {nd }}$ edition (EVT-2); Gray Silent Reading Test (GSRT); Rapid Letter naming (RLN); Test of Word Reading Efficiency (TOWRE): sight word reading (TOWRE-W) and phonemic decoding/nonword reading (TOWRE-P) and Test of Irregular Word Efficiency (TIWRE). 
Table 3. Model comparison between populations and standardised tests

\begin{tabular}{|c|c|c|c|}
\hline & Neurotypical vs Dyslexic & Neurotypical vs Stuttering & Dyslexic vs Stuttering \\
\hline Raven & $t(132)=-1.57, p=.12, d=-0.27$ & $t\left(37.15^{\mathrm{a}}\right)=0.74, p=.46, \Delta=0.14$ & $t\left(45.05^{\mathrm{a}}\right)=1.57, p=.12, \Delta=0.32$ \\
\hline GSRT & $t(132)=1.64, p=.10, d=0.29$ & $t(112)=-1.29, p=.20, d=-0.27$ & $t(78)=-2.11, p=.04, d=-0.49$ \\
\hline Total print exposure & $\boldsymbol{t}(80.09)=-0.94, p=.34, \Delta=-0.15$ & $t\left(34.39^{\mathrm{a}}\right)=-3.23, p=.002, \Delta=-0.63$ & $t\left(45.88^{\mathrm{a}}\right)=-2.56, p=.01, \Delta=-0.52$ \\
\hline BPVS-2 & $t(132)=0.25, p=.80, d=0.04$ & $t(112)=-1.82, p=.07, d=0.39$ & $t(78)=1.38, p=.17, d=0.31$ \\
\hline EVT-2 & $t(132)=-0.69, p=.49, d=-0.12$ & $t\left(35.91^{\mathrm{a}}\right)=-2.17, p=.04, \Delta=-0.41$ & $t\left(48.03^{\mathrm{a}}\right)=-1.61, p=.11, \Delta=-0.33$ \\
\hline TOWRE-W & $t(132)=4.10, p<.001, d=0.73$ & $t\left(35.28^{a}\right)=3.46, p=.0014, \Delta=0.66$ & $t\left(41.63^{\mathrm{a}}\right)=1.24, p=.22, \Delta=0.24$ \\
\hline TOWRE-P & $t(132)=7.69, p<.001, d=1.37$ & $t\left(34.38^{a}\right)=2.83, p=.007, \Delta=0.53$ & $t\left(43.86^{\mathrm{a}}\right)=-1.13, p=.27, \Delta=-0.23$ \\
\hline TIWRE & $t(132)=2.56, p=.01, d=0.46$ & $t\left(37.78^{a}\right)=-0.66, p=.52, \Delta=-0.13$ & $t(78)=-2.23, p=.03, d=-0.51$ \\
\hline Spelling & $t(132)=6.93, p<.001, d=1.24$ & $t\left(35.70^{a}\right)=1.97, p=.06, \Delta=0.37$ & $t\left(46.14^{\mathrm{a}}\right)=-1.84, p=.07, \Delta=-0.37$ \\
\hline Manual Stroop & $t(132)=-1.47, p=.14, d=-0.26$ & $t(112)=-0.48, p=.63, d=-0.10$ & $t(78)=0.66, p=.51, d=0.15$ \\
\hline Naming Stroop & $t(132)=-1.02, p=.31, d=-0.18$ & $t(112)=-0.56, p=.58, d=-0.12$ & $t(78)=0.27, p=.79, d=0.06$ \\
\hline Phoneme elision & $t\left(84.36^{a}\right)=2.66, p=.009, \Delta=0.43$ & $t\left(38.22^{a}\right)=2.23, p=.03, \Delta=0.43$ & $t(78)=0.33, p=.74, \Delta=0.07$ \\
\hline Memory for digits & $t(132)=6.12, p<.001, d=1.09$ & $t\left(39.22^{a}\right)=2.14, p=.04, \Delta=0.42$ & $t\left(44.18^{\mathrm{a}}\right)=-1.55, p=.13, \Delta=-0.31$ \\
\hline Nonword repetition & $t(132)=8.63, p<.001, d=1.54$ & $t\left(36.42^{\mathrm{a}}\right)=6.61, p<.001, \Delta=1.26$ & $t(78)=1.33, p=.19, \Delta=0.26$ \\
\hline RLN & $t(132)=-5.10, p<.001, d=-0.91$ & $t(112)=-2.69, p=.008, \Delta=-0.57$ & $t(78)=-1.23, p=.22, d=-0.28$ \\
\hline Phoneme reversal & $t(132)=5.37, p<.001, d=0.96$ & $t\left(38.94^{a}\right)=1.95, p=.06, \Delta=0.38$ & $t\left(43.75^{a}\right)=-1.25, p=.22, d=-0.32$ \\
\hline
\end{tabular}

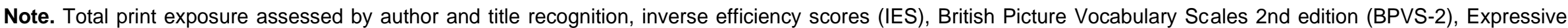

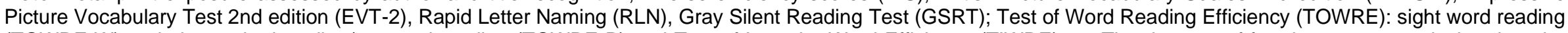

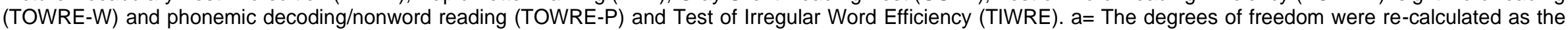
homogeneity of variance was unequal (Fligner-Killeen test of homogeneity of variance, n.d). Significant effects after Holm-Bonferroni correction are in bold. 

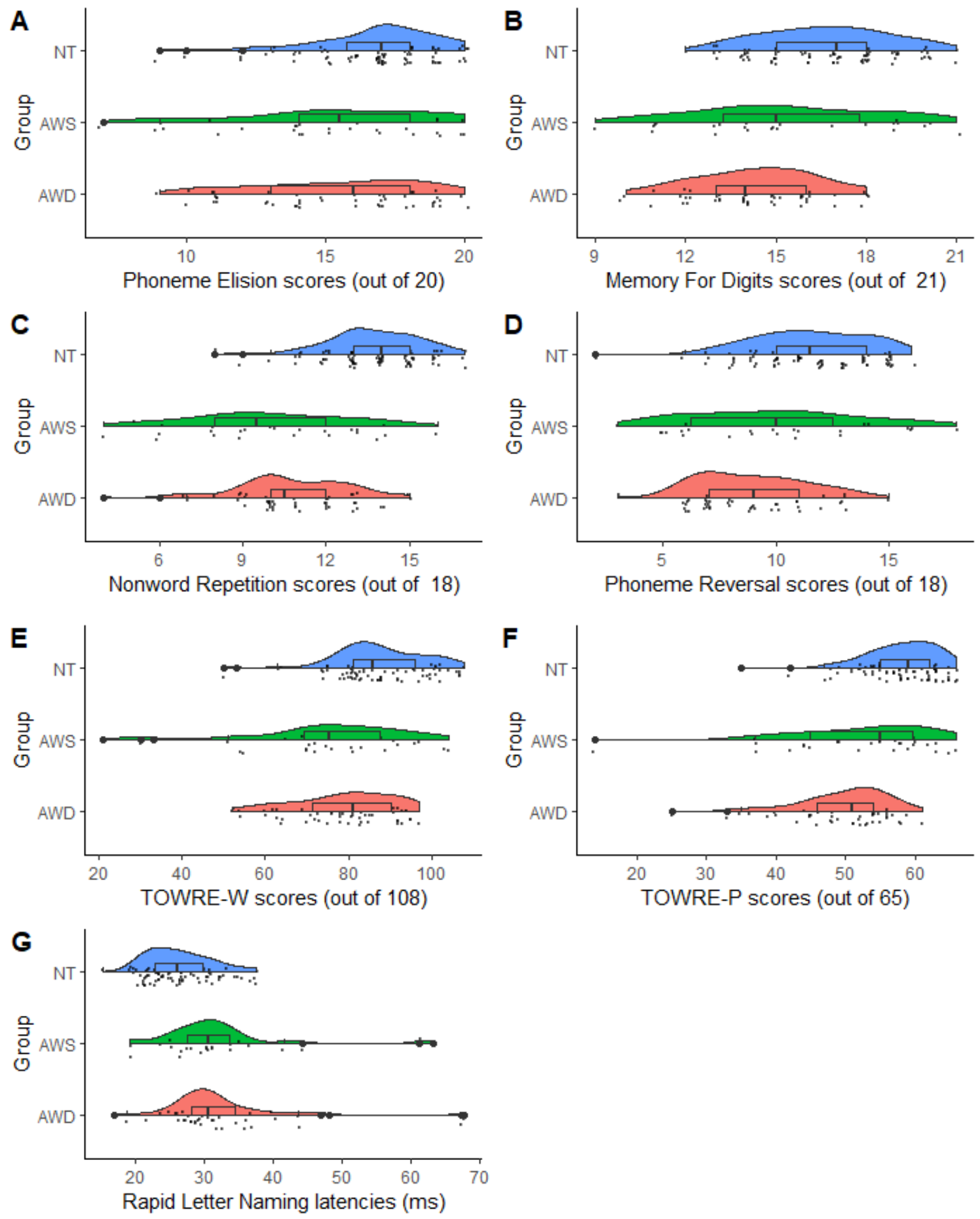

Figure 1. Mean proportion correct in Phoneme Elision, Memory for Digits, Nonword Repetition, Phoneme Reversal, TOWRE-W and TOWRE-P and the mean naming latencies of RLN for the neurotypical population (NT), adults with dyslexia (AWD) and adults who stutter (AWS). Each point represents a single participant, while the density plot above depicts the shape of the distribution.

8 The overlaid boxplots present summary statistics of the median (central, dark vertical line), first and 
9 third quartile (the left- and right-most ends of the boxes) and the range of the values, bounded to 10 within a distance of 1.5 times the inter-quartile range from the boxes (the whiskers). 
Post-hoc analyses. AWD performed worse than neurotypical participants on the spelling measure, with AWS not significantly different from either group. Note that poor spelling is a hallmark

13 feature of dyslexia, and it might be somewhat surprising to see AWS patterning somewhere in14 between the AWD and neurotypical group. While we are not aware of spelling being generally 15 problematic for AWS, Williams et al. (1969) did find that CWS performed (non-significantly) poorer on a spelling task than age-matched CWNS. There was no difference among the three groups in 17 the manual Stroop task, naming Stroop task, Raven, Gray Silent Reading Test (GSRT), Test of 18 Irregular Word reading (TIWRE), British Picture Vocabulary Scale (BPVS-2) and Expressive vocabulary scale (EVT-2). AWD did not differ from AWS in print exposure. Interestingly, AWS showed a significantly higher print exposure than the neurotypical population.

21 In a second batch of analyses we calculated composite scores for key measures (Silverstein, 22 1981). A composite measure of vocabulary (ZVocab) was formed by averaging the raw scores of 23 two strongly correlated vocabulary measures (i.e. EVT-2 and BPVS-2; $r=.61$ ) to provide a more 24 comprehensive measure of vocabulary ability. To form a composite measure of phonological 25 working memory (ZMemory), the raw scores of the two highly correlated measures of phonological working memory (i.e. nonword repetition and memory for digits; $r=.53$ ) were combined. In addition,

27 we included the raw scores of two highly correlated measures of reading fluency (TOWRE word 28 reading and phonemic decoding; $r=.67$ ) as one averaged measure as an assessment of reading fluency (ZReadingFluency). We found that AWD performed worse than the neurotypical population 30 on ZMemory $(t(132)=8.81, p<.001, d=1.57$, post-hoc power $>.99)$ and ZReadingFluency $31(t(132)=5.97, p<.001, d=1.07$, post-hoc power $>.99)$, but not $Z \operatorname{Vocab}(t(132)=-0.30, p=.77, d=-0.05$, 32 post-hoc power $=0.06$ ). Similarly, AWS performed worse than the neurotypical population on 33 ZMemory $(t(37.134)=4.90, \quad p<.001, d=1.30$, post-hoc power $>.99)$ and ZReadingFluency $34(t(34.61)=3.48, p=.001, d=0.99$, post-hoc post-hoc power $>.99)$, but not ZVocab $(t(36.22)=-0.61$, $35 p=.54, d=-0.17$, post-hoc power $=0.06$ ). There were no differences between AWD and AWS for $36 Z \operatorname{Vocab}(t(45.40)=-0.41, p=.68, d=-0.17$, post-hoc power $=0.11)$, ZMemory $(t(44.18)=-0.19, p=.85$,

$37 d=-0.05$, post-hoc power $=0.06)$ or ZReadingFluency $(t(78)=.48, p=.63, d=0.11$, post-hoc 38 power $=0.08)$. 


\section{Discussion}

40 We investigated several aspects of language processing (concretely, phonological awareness,

41 phonological retrieval, phonological working memory, and literacy skills) in adults with dyslexia

42 (AWD), adults who stutter (AWS), and fluent neurotypical participants. Our relatively large-scale

43 study has revealed a number of interesting findings. First, childhood stuttering is significantly higher

44 in AWD (34\%) than in neurotypical adults (1\%), while a co-occurrence rate of only about $5 \%$ to

$458.5 \%$ would have been expected. This was found to be moderated by the severity of dyslexia: the

46 more severe the dyslexia, the higher the probability of childhood stuttering. While our neurotypical

47 group showed a somewhat lower than expected stuttering-as-a-child rate (1\%) than the expected

$485 \%-8.5 \%$, the reason for this is unclear, though could be related to a lower percentage of AWS

49 entering higher education (Gerlach, Totty, Subramanian, \& Zebrowski, 2018).

50 Second, we found that the dyslexia profile was significantly higher in AWS (50\%) than in 51 neurotypical adults (2\%). Again, these numbers might be an underestimation as we would expect

$527-10 \%$ of the neurotypical participants to be dyslexic, though we again believe that this is related

53 to the fact that PWD are less likely to go to university (Pino \& Mortari, 2014). Together, these

54 findings provide strong evidence for an inter-dependency between dyslexia and stuttering that does

55 not result from a statistical artefact or how the conditions were defined (Bishop \& Snowling, 2004).

56 It is important to point out that the higher rate of co-occurrence for dyslexia and stuttering was found

57 in a college sample of high-functioning AWD, and our results will need to be assessed in a cross-

58 section of the general population to ensure that they are generalizable (Simons et al., 2017).

59 Third, as expected, the AWD group performed worse than the neurotypical group on measures

60 of phonological processing (phonological awareness, phonological working memory, and

61 phonological retrieval) and spelling. This was not related to differences in vocabulary level or

62 higher-level reading measures as they scored similar to neurotypical participants for expressive

63 and receptive vocabulary, reading comprehension and print exposure (for comparable results, see

64 Goulandris et al., 2000).

65 Fourth, and more surprisingly, AWS and AWD did not significantly differ on any of the (single 66 or composite) measures, and, with few exceptions, AWS performed worse than neurotypical 
67 participants on phonological measures. The exceptions are phoneme reversal, which approached 68 significance, and the TIWRE. Interestingly, the TIWRE measure was also the only of the selected 69 measures that did not correlate with stuttering severity. One possible reason for this absence of a 70 correlation might be that while the TIWRE involves overt articulation, its main purpose is to test 71 vocabulary and reading comprehension (Reynolds \& Kamphaus, 2007). Given that the groups did 72 not differ on more direct measures of vocabulary (BPVS-2 and EVT-2) and reading comprehension 73 (GSRT), it is not surprising that stuttering severity did not impact TIWRE performance. The only 74 non-phonological measure that showed a difference between AWS and neurotypical participants 75 was print exposure, with AWS performing better than neurotypical participants. One possibility is 76 that AWS read more than neurotypical participants as a way of dealing with social anxiety (Iverach 77 \& Rapee, 2014), which would explain the effect. Clearly, more research is needed to explore this 78 speculation in more depth (e.g. by including the OASES tool in the test battery).

79 The finding of an impairment in phonological awareness, phonological memory, and 80 phonological retrieval in AWS is in line with other works that points to certain phonological deficits 81 in people who stutter. For instance, Byrd et al. $(2012,2015)$ and Pelczarski and Yaruss (2014, 82 2016) found that people who stutter were less accurate in nonword repetition tasks and phoneme 83 elision tasks than people who do not stutter. These authors attributed these poor performances to 84 a difficulty in phonological encoding and/or subvocal rehearsal for people who stutter compared to 85 the neurotypical population. However, other stuttering research has shown no or only weak effects 86 in the behavioural data (e.g. Bakhtiar et al., 2009; Smith et al., 2012). We believe that one strength 87 of our study is the inclusion of a larger and more diverse number of language tests. In addition, the 88 finding that the phonological profiles in AWS and AWD were indistinguishable, together with the 89 finding that a much larger than expected number of AWD stuttered as a child, points to the intriguing 90 possibility that dyslexia and stuttering may share an underlying phonological deficit. Further support 91 for the idea that dyslexia and stuttering might, at some level, be related comes from shared genetic 92 risk factors (Chen et al., 2014, 2015), overlapping brain impairment (Chang et al., 2008; Chang et 93 al., 2015; Choo \& Chang, 2017; Richlan, 2012; Richlan et al., 2009, 2011, 2013; Rimrodt et al., 94 2010; see review by Vandermosten et al., 2012), and possibly the fact that both young PWS (Arndt 
95 \& Healy, 2001; Blood et al., 2003, Wolk et al., 1993) and children genetically at risk of dyslexia

96 show phonological difficulties (Gallagher et al., 2000).

97 There are a number of caveats related to our study. First, while all participants were young adults, the AWS group was, on average, 9 years older. In addition, in contrast to the AWD and AWS group, the neurotypical group was predominantly female. It is unclear if, or to what extent, this imbalance affected the results. To our knowledge, there have been no reports of gender differences for the standardised tests which we used ${ }^{5}$, nor of differences within the restricted age range tested. Second, it is well-known that AWS tend to perform worse under time pressure (Perkins et al., 1991). However, of the 7 tests that showed a difference between PWS and neurotypical participants, 4 did not have any time constraint and for 2 tests, the time constraint was significantly increased (from 45 seconds for AWD and controls to 3 minutes for AWS). The only other task, RLN, had no time constraint though participants had to name letters as quickly as possible. Third, while the certified educational reports indicated childhood stuttering in $34 \%$ of questionnaire did not provide an educational report, which may have led to an underestimation of

111 prevalence rates for the neurotypical population. (Nevertheless, even the expected $5 \%$ or $8.5 \%$

112 childhood stuttering prevalence typically found in a neurotypical population falls far short of the $34 \%$

113 found in our AWD sample). In order to address these shortcomings and in order to get concurrent

114 data and reduce the retrospective nature of reporting by adults, future studies with a longitudinal 115 design, using a creative destruction approach (i.e. pre-specifying alternative results by competing 116 hypotheses on a complex set of experimental findings; Tierney et al., 2020a, 2020b) are needed.

\footnotetext{
${ }^{5}$ We also compared the performance of only the females in the three groups. Despite the small sample size, female neurotypical participants performed better than female AWD and AWS for all phonological processing measures, except for phoneme elision. Female AWD and AWS performed similarly on tests of phonological processing and reading fluency, mirroring the results found for the groups as a whole. In addition, we compared the performance of age-matched individuals in the three groups. Again, despite the small sample size, we found the same pattern of results between the neurotypical group and AWS, except for TOWRE-P and phoneme elision. When comparing AWD to AWS for this subgroup, the same pattern was found as for the group as a whole, except that AWS showed a smaller manual Stroop effect than AWD.
} 
118 AWS and AWD should be carefully monitored, as these individuals are at increased risk of speech,

119 language and literacy impairments. In addition, screening on a measure of phonological 120 processing, such as nonword repetition, and a measure of broader articulatory or fluency skills, 121 such as the TOWRE, would allow practitioners to identify individuals at risk of different literacy and 122 fluency difficulties and provide appropriate support for PWS and PWD. Finally, we suggest that the 123 childhood stuttering profile in AWD, together with the dyslexia profile in AWS, should be evaluated 124 in all future studies assessing language-based processes in these groups.

125 In conclusion, we have shown that the rate of childhood stuttering in PWD is much higher than 126 expected (34 times higher in our sample) and that $50 \%$ of our AWS fulfilled the diagnostic criteria 127 of dyslexia (5 to 7 times higher than in the general population). In addition, AWD and AWS showed 128 similarly poor performance on several measures of phonological and articulatory processing 129 compared to neurotypical participants. Together these results suggest that dyslexia and stuttering 130 might be more similar than previously assumed and may share a phonological deficit.

\section{Acknowledgments}

134 There were no conflicts of interest. We would like to thank the Stammer Trust for funding the 135 research to recruit PWS, the student support services at the Universities of Birmingham, Leicester 136 and Warwick for the recruitment of PWD and PWS, the Birmingham Stammering Network and 137 Stamma for the recruitment of additional PWS. We thank our participants for being involved in the 138 study.

139 Author notes: M.M.E. collected and curated the data and analysed the results. Supervision of 140 these activities was provided by S.F. and L.W. M.M.E., S.F. and L.W. conceptualised the idea, 141 wrote and proofread the manuscript. 


\section{References}

Ajdacic-Gross, V., Vetter, S., Müller, M., Kawohl, W., Frey, F., Lupi, G., ... \& Rössler, W. (2010). Risk factors for stuttering: a secondary analysis of a large data base. European Archives of Psychiatry and Clinical Neuroscience, 260(4), 279-286. https://doi.org/10.1007/s00406-0090075-4

Ajdacic-Gross, V., Bechtiger, L., Rodgers, S., Müller, M., Kawohl, W., von Känel, R., ... \& Strippoli, M. P. F. (2018). Subtypes of stuttering determined by latent class analysis in two Swiss epidemiological surveys. PloS One, 13(8), e0198450. https://doi.org/10.1371/journal.pone.0198450

Ambrose, N. G., Yairi, E., Loucks, T. M., Seery, C. H., \& Throneburg, R. (2015). Relation of motor, linguistic and temperament factors in epidemiologic subtypes of persistent and recovered stuttering: Initial findings. Journal of Fluency Disorders, 45, 12-26. https://doi.org/10.1016/i.jfludis.2015.05.004

Anderson, J. D., \& Wagovich, S. A. (2010). Relationships among linguistic processing speed, phonological working memory, and attention in children who stutter. Journal of fluency disorders, 35(3), 216-234. https://doi.org/10.1016/i.jfludis.2010.04.003

Anderson, J. D., Wagovich, S. A., \& Hall, N. E. (2006). Nonword repetition skills in young children who do and do not stutter. Journal of fluency disorders, 31(3), 177-199. https://doi.org/10.1016/j.jfludis.2006.05.001

Ardila, A., Bateman, J., Niño, C. R., Pulido, E., Rivera, D. B., \& Vanegas, C. J. (1994). An epidemiologic study of stuttering. Journal of Communication Disorders, 27(1), 37-48. https://doi.org/10.1016/0021-9924(94)90009-4

Arndt, J., \& Healey, E. C. (2001). Concomitant disorders in school-age children who stutter. Language, Speech, and Hearing Services in Schools, 32 (2), 68-78. https://doi.org/10.1044/0161-1461(2001/006) 
Bakhtiar, M., Abad Ali, D., \& Sadegh, S. (2007). Nonword repetition ability of children who do and do not stutter and covert repair hypothesis. Indian Journal of Medical Sciences, 61(8), $462-$ 470. https://doi.org/10.1016/j.jfludis.2006.05.001

Bishop, D. V. M. (1990). Handedness and developmental disorder. Oxford, UK: Blackwell.

Bishop, D.V., \& Snowling, M.J. (2004). Developmental dyslexia and specific language impairment: Same or different?, Psychological Bulletin, 130(6), 858-886. DOI: $10.1037 / 0033-2909.130 .6 .858$

Blood, G. W., Ridenour Jr, V. J., Qualls, C. D., \& Hammer, C. S. (2003). Co-occurring disorders in children who stutter. Journal of Communication Disorders, 36(6), 427-448. https://doi.org/10.1016/S0021-9924(03)00023-6

Bosshardt, H. G. (1993). Differences between stutterers' and nonstutterers' short-term recall and recognition performance. Journal of Speech, Language, and Hearing Research, 36(2), 286293. https://doi.org/10.1044/ishr.3602.286

Bosshardt, H. G., Ballmer, W., \& de Nil, L. (2002). Effects of category and rhyme decisions on sentence production. Journal of speech, language, and hearing research, 45(2), 844-857. https://doi.org/10.1044/1092-4388(2002/068)

Bowers, A., Bowers, L. M., Hudock, D., \& Ramsdell-Hudock, H. L. (2018). Phonological working memory in developmental stuttering: potential insights from the neurobiology of language and cognition. Journal of Fluency Disorders, 58, 94-117. https://doi.org/10.1016/i.jfludis.2018.08.006

Bowey, J. A., \& Rutherford, J. (2007). Imbalanced word-reading profiles in eighth-graders. Journal of Experimental Child Psychology, 96(3), 169-196. https://doi.org/10.1016/j.jecp.2006.11.001

Bradley, L., \& Bryant, P. E. (1983). Categorizing sounds and learning to read-a causal connection. Nature, 301(5899), 419. doi:10.1038/301419a0

Bruyer, R., \& Brysbaert, M. (2011). Combining speed and accuracy in cognitive psychology: Is the inverse efficiency score (IES) a better dependent variable than 
the mean reaction time (RT) and percentage of errors (PE)? Psychologica Belgica. 51(1), 5-13.

Burger, R., \& Wijnen, F. (1999). Phonological encoding and word stress in stuttering and nonstuttering subjects. Journal of fluency disorders, 24(2), 91-106. https://doi.org/10.1016/S0094-730X(98)00028-X

Byrd, C. T., Conture, E. G., \& Ohde, R. N. (2007). Phonological priming in young children who stutter: Holistic versus incremental processing. American Journal of Speech-Language Pathology, 16(1), 43-53. https://doi.org/10.1044/1058-0360(2007/006)

Byrd, C. T., McGill, M., \& Usler, E. (2015). Nonword repetition and phoneme elision in adults who do and do not stutter: Vocal versus nonvocal performance differences. Journal of Fluency Disorders, 44, 17-31. https://doi.org/10.1016/j.jfludis.2015.01.004

Byrd, C. T., Vallely, M., Anderson, J. D., \& Sussman, H. (2012). Nonword repetition and phoneme elision in adults who do and do not stutter. Journal of fluency disorders, 37(3), 188-201. https://doi.org/10.1016/.j.jludis.2012.03.003

Chang, S. E., Erickson, K. I., Ambrose, N. G., Hasegawa-Johnson, M. A., \& Ludlow, C. L. (2008). Brain anatomy differences in childhood stuttering. Neuroimage, 39(3), 1333-1344. https://doi.org/10.1016/..neuroimage.2007.09.067

Chang, S. E., Zhu, D. C., Choo, A. L., \& Angstadt, M. (2015). White matter neuroanatomical differences in young children who stutter. Brain, 138(3), 694-711. https://doi.org/10.1093/brain/awu400

Chateau, D., \& Jared, D. (2000). Exposure to print and word recognition processes. Memory \& Cognition, 28(1), 143-153. https://doi.org/10.3758/BF03211582

Chen, H., Wang, G., Xia, J., Zhou, Y., Gao, Y., Xu, J., ... \& Sun, Y. (2014). Stuttering candidate genes DRD2 but not SLC6A3 is associated with developmental dyslexia in Chinese population. Behavioral and Brain Functions, 10(1), 1-10. doi:10.1186/1744-9081-10-29

Chen, H., Xu, J., Zhou, Y., Gao, Y., Wang, G., Xia, J., ... \& Sun, Y. (2015). Association study of stuttering candidate genes GNPTAB, GNPTG and NAGPA with dyslexia in Chinese population. BMC Genetics, 16(1), 1-7. doi: 10.1186/s12863-015-0172-5. 
225 Choopanian, F., Farazi, M., Qoreishi, Z., Rahmati, A., Ghaedamini, G., \& Ilkhani, Z.

226 (2019). Evaluating the Word/Non-Word Repetition in Adults With Stuttering Based on Stuttering Severity and Length of Words/Non-Words. Journal of Modern Rehabilitation, 13(4), 199-206. https://doi.org/10.32598/JMR.13.4.199

Chow, H. M., \& Chang, S. E. (2017). White matter developmental trajectories associated with persistence and recovery of childhood stuttering. Human Brain Mapping, 38(7), 3345-3359. https://doi.org/10.1002/hbm.23590

232 Coalson, G. A., \& Byrd, C. T. (2016). Phonetic complexity of words immediately following 56-69. https://doi.org/10.1016/.j.fludis.2015.10.002

Coalson, G. A., \& Byrd, C. T. (2017). Nonword repetition in adults who stutter: The effects of stimuli stress and auditory-orthographic cues. PloS One, 12(11), 1-21. https://doi.org/10.1371/journal.pone.0188111

Coalson, G. A., \& Byrd, C. T. (2020). Delayed silent phoneme monitoring in adults who do and do not stutter. Speech, Language and Hearing, 23(2), 37-54. https://doi.org/10.1080/2050571X.2018.1458067

Cortese, M. J., \& Simpson, G. B. (2000). Regularity effects in word naming: What are they?. Memory \& Cognition, 28(8), 1269-1276. https://doi.org/10.3758/BF03211827

Craig, A., Hancock, K., Tran, Y., Craig, M., \& Peters, K. (2002). Epidemiology of stuttering in the community across the entire life span. Journal of Speech, Language, and Hearing Research, 45(6), 1097-1105. https://doi.org/10.1044/1092-4388(2002/088)

Cunningham, A. E., \& Stanovich, K. E. (1990). Assessing print exposure and orthographic processing skill in children: A quick measure of reading experience. Journal of Educational Psychology, 82(4), 733-740. doi: 10.1037/0022-0663.82.4.733

de Bree, E., Wijnen, F., \& Gerrits, E. (2010). Non-word repetition and literacy in Dutch children atrisk of dyslexia and children with SLI: Results of the follow-up study. Dyslexia, 16(1), 3644. https://doi.org/10.1002/dys.395 
252 Dunn, L., Dunn, L., Whetton, C., \& Burley, J. (1997). British Picture Vocabulary Scale II. GL 253 Assessment: London.

254 Eglinton, E., \& Annett, M. (1994). Handedness and dyslexia: A meta-analysis. Perceptual and 255 motor skills, 79(3_suppl), 1611-1616. https://doi.org/10.2466/pms.1994.79.3f.1611

256 Elliott, C. D., Smith, P., \& McCulloch, K. (1996). British Ability Scales second edition (BAS II):

257 administration and scoring manual. London: NFER-Nelson.

258 Elsherif, M., Wheeldon, L. R., \& Frisson, S. (2020a). Phonological precision for word recognition

259 in skilled readers. https://doi.org/10.31234/osf.io/vftxd

260 Elsherif, M., Wheeldon, L., \& Frisson, S. (2020b). Effects of individual differences in lexical

261 quality: Neighbourhood effects in naming. https://doi.org/10.31234/osf.io/gpk9m

262 Faul, F., Erdfelder, E., Buchner, A., \& Lang, A. (2009). Statistical power analyses using G*Power

263 3.1: Tests for correlation and regression analyses. Behavior Research Methods, 41(4),

$264 \quad 1149-1160$. doi:10.3758/brm.41.4.1149

265 Gallagher, A., Frith, U., \& Snowling, M. J. (2000). Precursors of literacy delay among children at

266 genetic risk of dyslexia. The Journal of Child Psychology and Psychiatry and Allied Disciplines, 41(2), 203-213. DOI: https://doi.org/10.1017/S0021963099005284

Gerlach, H., Totty, E., Subramanian, A., \& Zebrowski, P. (2018). Stuttering and labor market outcomes in the United States. Journal of Speech, Language, and Hearing Research, 61(7), 1649-1663. https://doi.org/10.1044/2018 JSLHR-S-17-0353

Gerwin, K. L., \& Weber, C. (2020). Neural Indices Mediating Rhyme Discrimination Differ for Some Young Children Who Stutter Regardless of Eventual Recovery or

275 Goulandris, N. K., Snowling, M. J., \& Walker, I. (2000). Is dyslexia a form of specific language 276 impairment? A comparison of dyslexic and language impaired children as adolescents. Annals of Dyslexia, 50(1), 103-120. https://doi.org/10.1007/s11881-000-0019-1

278 Guitar, B. (2013). Stuttering: An integrated approach to its nature and treatment. Lippincott $279 \quad$ Williams \& Wilkins. 
Hakim, H. B., \& Ratner, N. B. (2004). Nonword repetition abilities of children who stutter: An exploratory study. Journal of fluency disorders, 29(3), 179-199. https://doi.org/10.1016/j.jfludis.2004.06.001

Hanley, J. R. (1997). Reading and spelling impairments in undergraduate students with developmental dyslexia. Journal of Research in Reading, 20(1), 22-30. https://doi.org/10.1111/1467-9817.00017

Hennessey, N. W., Nang, C. Y., \& Beilby, J. M. (2008). Speeded verbal responding in adults who stutter: Are there deficits in linguistic encoding?. Journal of fluency disorders, 33(3), 180-202. https://doi.org/10.1016/i.jfludis.2008.06.001

Howell, T. A., \& Ratner, N. B. (2018). Use of a phoneme monitoring task to examine lexical access in adults who do and do not stutter. Journal of Fluency Disorders, 57, 65-73. https://doi.org/10.1016/j.jfludis.2018.01.001

Huettig, F., Lachmann, T., Reis, A., \& Petersson, K. M. (2018). Distinguishing cause from effectmany deficits associated with developmental dyslexia may be a consequence of reduced and suboptimal reading experience. Language, Cognition and Neuroscience, 33(3), 333350. https://doi.org/10.1080/23273798.2017.1348528

Iverach, L., \& Rapee, R. M. (2014). Social anxiety disorder and stuttering: Current status and future directions. Journal of Fluency Disorders, 40, 69-82. https://doi.org/10.1016/j.jludis.2013.08.003

Janssen, P., Kraaimaat, F., \& Van der Meulen, S. (1983). Reading ability and disfluency in stuttering and nonstuttering elementary school children. Journal of Fluency Disorders, 8(1), 39-53. https://doi.org/10.1016/0094-730X(83)90020-7

Lavidor, M., \& Ellis, A. (2003). Orthographic and phonological priming in the two cerebral hemispheres. Laterality: Asymmetries of Body, Brain and Cognition, 8(3), 201-223. https://doi.org/10.1080/13576500143000203

Malek, A., Amiri, S., Hekmati, I., Pirzadeh, J., \& Gholizadeh, H. (2013). A comparative study on diadochokinetic skill of dyslexic, stuttering, and normal children. ISRN Paediatrics, 2013, 17. 
Mahesh, S., Geetha, M. P., Amulya, S., \& Ravel, H. M. N. (2018). Phonological Encoding in Children who Stutter. Global Journal of Otolaryngology, 17(5).

Melby-Lervåg, M., \& Lervåg, A. (2012). Oral language skills moderate nonword repetition skills in children with dyslexia: A meta-analysis of the role of nonword repetition skills in dyslexia. Scientific Studies of Reading, 16(1), 1-34. https://doi.org/10.1080/10888438.2010.537715

Melby-Lervåg, M., Lyster, S. A. H., \& Hulme, C. (2012). Phonological skills and their role in learning to read: a meta-analytic review. Psychological Bulletin, 138(2), 322-352. http://dx.doi.org/10.1037/a0026744

Melnick, K. S., Conture, E. G., \& Ohde, R. N. (2003). Phonological priming in picture naming of young children who stutter. Journal of Speech, Language, and Hearing Research, 46(6), 1426-1443. https://doi.org/10.1044/1092-4388(2003/111)

Mohan, R., \& Weber, C. (2015). Neural systems mediating processing of sound units of language distinguish recovery versus persistence in stuttering. Journal of Neurodevelopmental Disorders, 7(1), 28. https://doi.org/10.1186/s11689-015-9124-7

Mol, S. E., \& Bus, A. G. (2011). To read or not to read: a meta-analysis of print exposure from infancy to early adulthood. Psychological bulletin, 137(2), 267-296. https://doi.org/10.1037/a0021890.

Navarro, D. J. (2015). Learning statistics with R: A tutorial for psychology students and other beginners. Adelaide, SA: University of Adelaide.

Nogueira, P. R., Oliveira, C. M. C. D., Giacheti, C. M., \& Moretti-Ferreira, D. (2015). Familial persistent developmental stuttering: disfluencies and prevalence. Revista CEFAC, 17(5), 1441-1448. https://doi.org/10.1590/1982-0216201517510214

Ntourou, K., Conture, E. G., \& Lipsey, M. W. (2011). Language abilities of children who stutter: A meta-analytical review. American Journal of Speech-Language Pathology, 20(3), 163-179. https://doi.org/10.1044/1058-0360(2011/09-0102) 
334 O'Brian, S., Jones, M., Packman, A., Menzies, R., \& Onslow, M. (2011). Stuttering severity and 335 educational attainment. Journal of Fluency Disorders, 36(2), 86-92.

$336 \quad$ https://doi.org/10.1016/j.jfludis.2011.02.006

337 Oyoun, H. A., El Dessouky, H., Shohdi, S., \& Fawzy, A. (2010). Assessment of working memory

338 in normal children and children who stutter. Journal of American Science, 6(11), 562-6.

339 Paden, E. P., Ambrose, N. G., \& Yairi, E. (2002). Phonological progress during the first 2 years of

$340 \quad$ stuttering. Journal of Speech, Language, and Hearing Research, 45(2), 256-267.

$341 \quad$ https://doi.org/10.1044/1092-4388(2002/020)

342 Paden, E. P., Yairi, E., \& Ambrose, N. G. (1999). Early childhood stuttering II: Initial status of

343 phonological abilities. Journal of Speech, Language, and Hearing Research, 42(5), 1113-

344 1124. https://doi.org/10.1044/jslhr.4205.1113

345 Pelczarski, K. M., \& Yaruss, J. S. (2016). Phonological memory in young children who

346 stutter. Journal of Communication Disorders, 62, 54-66.

$347 \quad$ https://doi.org/10.1016/i.jcomdis.2016.05.006

348 Pelczarski, K. M., \& Yaruss, J. S. (2014). Phonological encoding of young children who stutter.

349 Journal of Fluency Disorders, 39, 12-24. doi: 10.1016/j.jfludis.2013.10.003

350 Pennington, B. F., Santerre-Lemmon, L., Rosenberg, J., MacDonald, B., Boada, R., Friend, A., ...

351 \& Olson, R. K. (2012). Individual prediction of dyslexia by single versus multiple deficit

352 models. Journal of Abnormal Psychology, 121(1), 212--224.

$353 \quad$ https://doi.org/10.1037/a0025823.

354 Perkins, W. H., Kent, R. D., \& Curlee, R. F. (1991). A theory of neuropsycholinguistic function in

355 stuttering. Journal of Speech, Language, and Hearing Research, 34(4), 734-752.

$356 \quad$ https://doi.org/10.1044/jshr.3404.734

357 Peter, B., Lancaster, H., Vose, C., Middleton, K., \& Stoel-Gammon, C. (2018). Sequential

358 processing deficit as a shared persisting biomarker in dyslexia and childhood apraxia of

$359 \quad$ speech. Clinical linguistics \& phonetics, 32(4), 316-346.

$360 \quad$ https://doi.org/10.1080/02699206.2017.1375560 
361 Peterson, R.L., \& Pennington, B.F. (2012) Developmental dyslexia. Lancet, 379, 1997-2007.

$362 \quad$ https://doi.org/10.1016/S0140-6736(12)60198-6

363 Pino, M., \& Mortari, L. (2014). The inclusion of students with dyslexia in higher education: A

364 systematic review using narrative synthesis. Dyslexia, 20(4), 346-369.

$365 \quad$ https://doi.org/10.1002/dys.1484

366 Price, P. C., Jhangiani, R. S., \& Chiang, I. A. (2015). Research methods in psychology: 2nd

367 Canadian edition. BC Campus, OpenEd. Retrieved from

368 https://opentextbc.ca/researchmethods/

369 R Core Team. (2016). R: A Language and Environment for Statistical Computing. Vienna: R

$370 \quad$ Foundation for Statistical Computing.

371 Ransby, M.J., \& Swanson, H.L. (2003). Reading comprehension skills of young adults with

372 childhood diagnoses of dyslexia. Journal of Learning Disabilities, 36(6), 538-555.

$373 \quad$ https://doi.org/10.1177/00222194030360060501.

374 Raven, J.C. (1960). Guide to using the Standard Progressive Matrices. London: Lewis.

375 Reid, G. (2012). The Routledge companion to dyslexia. Routledge.

376 Reynolds, C. R., \& Kamphaus, R. (2007). TIWRE: Test of Irregular Word Reading Efficiency.

377 Psychological Assessments Resources.

378 Richlan, F. (2012) Developmental dyslexia: Dysfunction of a left hemisphere reading network.

379 Frontiers in Human Neuroscience, 6 (120), 1-5. doi: 10.3389/fnhum.2012.00120.

380 Richlan, F., Kronbichler, M., \& Wimmer, H. (2009). Functional abnormalities in the dyslexic brain:

381 A quantitative meta-analysis of neuroimaging studies. Human Brain Mapping, 30(10), 3299-

382 3308. doi: 10.1002/hbm.20752.

383 Richlan, F., Kronbichler, M., \& Wimmer, H. (2011). Meta-analyzing brain dysfunctions in dyslexic

$384 \quad$ children and adults. Neuroimage, 56(3), 1735-1742. doi:

$385 \quad$ 10.1016/j.neuroimage.2011.02.040.

386 Richlan, F., Kronbichler, M., \& Wimmer, H. (2013). Structural abnormalities in the dyslexic brain:

387 a meta-analysis of voxel-based morphometry studies. Human Brain Mapping, 34(11), 3055-

388 3065. https://doi.org/10.1002/hbm.22127 
Riley, G. D. (1994). Stuttering severity instrument for children and adults, (SSI-3). Austin, TX: Pro-ed.

391 Rimrodt, S. L., Peterson, D. J., Denckla, M. B., Kaufmann, W. E., \& Cutting, L. E. (2010). White matter microstructural differences linked to left perisylvian language network in children with dyslexia. Cortex, 46(6), 739-749. https://doi.org/10.1016/i.cortex.2009.07.008

Roodenrys, S., \& Stokes, J. (2001). Serial recall and nonword repetition in reading disabled children. Reading and Writing, 14(5-6), 379-394. https://doi.org/10.1023/A:1011123406884

Sasisekaran J. \& Byrd C.T. (2013). A preliminary investigation of segmentation and rhyme abilities of children who stutter. Journal of Fluency Disorders, 38, 222-234. https://doi.org/10.1016/j.jfludis.2012.12.004

Sasisekaran, J., \& De Nil, L. F. (2006). Phoneme monitoring in silent naming and perception in adults who stutter. Journal of Fluency Disorders, 31(4), 284-302. https://doi.org/10.1016/j.jfludis.2006.08.001

Sasisekaran, J., De Nil, L. F., Smyth, R., \& Johnson, C. (2006). Phonological encoding in the silent speech of persons who stutter. Journal of Fluency Disorders, 31(1), 1-21. https://doi.org/10.1016/j.jfludis.2005.11.005

Seery, C., Watkins, R., Ambrose, N., \& Throneburg (2006). Nonword repetition by school-age children who stutter. Poster Presented at the Annual Meeting of the American Speech-Language and Hearing Association (ASHA) Convention.

Share, D. L. (1995). Phonological recoding and self-teaching: Sine qua non of reading acquisition. Cognition, 55(2), 151-218. https://doi.org/10.1016/0010-0277(94)00645-2

Signorell, A., Aho, K., Alfons, A., Anderegg, N., Aragon, T., \& Arppe, A. (2019). DescTools: Tools for descriptive statistics: R package version 0.99.28. Vienna: R Foundation for Statistical Computing.

Simons, D.J., Shoda, Y., \& Lindsay, D.S. (2017). Constraints on Generality (COG): A proposed addition to all empirical papers. Perspectives on Psychological Science, 12, 1125-1128. https://doi.org/10.1177/1745691617708630 
416 Smith, A., Goffman, L., Sasisekaran, J., \& Weber-Fox, C. (2012). Language and motor abilities of

417 preschool children who stutter: Evidence from behavioral and kinematic indices of nonword

418 repetition performance. Journal of fluency disorders, 37(4), 344-358.

$419 \quad$ https://doi.org/10.1016/i.jfludis.2012.06.001

420 Smith, A., \& Weber, C. (2017). How stuttering develops: The multifactorial dynamic pathways

421 theory. Journal of Speech, Language, and Hearing Research, 60(9), 2483-2505.

$422 \quad$ https://doi.org/10.1044/2017 JSLHR-S-16-0343

423 Spencer, C., \& Weber-Fox, C. (2014). Preschool speech articulation and nonword repetition

424 abilities may help predict eventual recovery or persistence of stuttering. Journal of fluency

425 disorders, 41, 32-46. https://doi.org/10.1016/j.jfludis.2014.06.001

426 Szenkovits, G., \& Ramus, F. (2005). Exploring dyslexics' phonological deficit I: lexical vs sub-

$427 \quad$ lexical and input vs output processes. Dyslexia, 11(4), 253-268.

$428 \quad$ https://doi.org/10.1002/dys.308

429 Snowling, M.J. Dyslexia. (2000). Second Edition. Oxford: Blackwell Publishers.

430 Snowling, M.J., \& Melby-Lervag, M. (2016). Oral language deficits in familial dyslexia: A meta-

$431 \quad$ analysis and review. Psychological Bulletin, 142(5), 498-545. doi: 10.1037/bul0000037

432 Stanovich, K. E., \& West, R. F. (1989). Exposure to print and orthographic processing. Reading

433 Research Quarterly, 24(4), 402-433. DOI: 10.2307/747605

434 Starkweather, C. W. (2002). The epigenesis of stuttering. Journal of Fluency Disorders, 27(4),

435 269-288. https://doi.org/10.1016/S0094-730X(02)00144-4

436 Stroop, J. R. (1935). Studies of interference in serial verbal reactions. Journal of Experimental 437 Psychology, 18(6), 643-662.

438 Tierney, W., Hardy III, J. H., Ebersole, C. R., Leavitt, K., Viganola, D., Clemente, E. G., ... \&

439 Uhlmann, E. L. (2020a). Creative destruction in science. Organizational Behavior and

$440 \quad$ Human Decision Processes, 161, 291-309. https://doi.org/10.1016/j.obhdp.2020.07.002

441 Tierney, W., Hardy, J. H., Ebersole, C. R., Viganola, D., Clemente, E. G., Gordon, D. M., ... \&

442 Pfeiffer, T. (2020b). A creative destruction approach to replication: Implicit work and sex

443 morality across cultures. Journal of Experimental Social Psychology. 
Torchiano, M. (2017). Package 'effsize'. Available at https://cran.rproject.org/web/packages/effsize/effsize.pdf

Torgesen, J. K., Rashotte, C. A., \& Wagner, R. K. (1999). TOWRE: Test of word reading efficiency. Austin, TX: Pro-ed.

Townsend, J.T., \& Ashby, F.G. (1978). Methods of modelling capacity in simple processing systems. In J.Castellan, \& F.Restle (Vol. Eds.), Cognitive Theory: Vol.3. (pp. 200-239). Hillsdale. N.J: Erlbaum.

Vandermosten, M., Boets, B., Wouters, J., \& Ghesquière, P. (2012). A qualitative and quantitative review of diffusion tensor imaging studies in reading and dyslexia. Neuroscience \& Biobehavioral Reviews, 36(6), 1532-1552. https://doi.org/10.1016/j.neubiorev.2012.04.002

Vincent, I. (2017). Semantic and Phonological Encoding in Adults Who Stutter: Silent Responses to Pictorial Stimuli. Journal of Speech, Language, and Hearing Research, 60(9), 25372550. https://doi.org/10.1044/2017 JSLHR-S-16-0323

Vincent, I., Grela, B. G., \& Gilbert, H. R. (2012). Phonological priming in adults who stutter. Journal of fluency disorders, 37(2), 91-105. https://doi.org/10.1016/j.jfludis.2012.01.001

Vlachos, F., Avramidis, E., Dedousis, G., Chalmpe, M., Ntalla, I., \& Giannakopoulou, M. (2013). Prevalence and gender ratio of dyslexia in Greek adolescents and its association with parental history and brain injury. American Journal of Educational Research, 1(1), 22-25. DOI: 10.12691/education-1-1-5

Wagner, R. K., Torgesen, J. K., \& Rashotte, C. A. (1999). Comprehensive test of phonological processing: CTOPP. Pro-ed.

Walsh, B., Usler, E., Bostian, A., Mohan, R., Gerwin, K. L., Brown, B., ... \& Smith, A. (2018, September). What are predictors for persistence in childhood stuttering?. In Seminars in speech and language (Vol. 39, No. 4, p. 299). NIH Public Access.

Watkins, K. E., Smith, S. M., Davis, S., \& Howell, P. (2007). Structural and functional abnormalities of the motor system in developmental stuttering. Brain, 131(1), 50-59. https://doi.org/10.1093/brain/awm241 
472 Weber-Fox, C., Spencer, R. M., SpruillIII, J. E., \& Smith, A. (2004). Phonologic processing in

473 adults who stutter. Journal of Speech, Language, and Hearing Research, 47(6),1244-1258.

$474 \quad$ https://doi.org/10.1044/1092-4388(2004/094)

475 Wickham, H. (2017). Tidyverse: Easily Install and Load 'Tidyverse' Packages. R Package Version

476 1.1.1. Available at: $\underline{\text { https://CRAN.R-project.org/package=tidyverse. }}$.

477 Widerholt, J. L., \& Blalock, G. (2000). GSRT: Gray Silent Reading Tests. Pro-Ed.

478 Williams, K. T. (2007). EVT-2: Expressive vocabulary test. Pearson Assessments.

479 Williams, D. E., Melrose, B. M., \& Woods, C. L. (1969). The relationship between stuttering and 480 academic achievement in children. Journal of Communication Disorders, 2(2), 87-98.

481 https://doi.org/10.1016/0021-9924(69)90032-X

482 Wolk, L., Edwards, M.L., \& Conture, E.G. (1993). Coexistence of stuttering and disordered

483 phonology in young children. Journal of Speech and Hearing Research 36, 906-917

$484 \quad$ https://doi.org/10.1044/ishr.3605.906

485 Yairi, E. (2007). Subtyping stuttering I: A review. Journal of Fluency Disorders, 32(3), 165-196.

$486 \quad$ https://doi.org/10.1016/j.jfludis.2007.04.001

487 Yairi, E., \& Ambrose, N. (2013). Epidemiology of stuttering: 21st century advances. Journal of

488 Fluency Disorders, 38(2), 66-87. https://doi.org/10.1016/j.jfludis.2012.11.002

489 
490 Mahmoud Medhat Elsherif, MSc is a PhD candidate in the Department of Psychology at the 491 University of Birmingham. His primary research is to assess the similarities and differences 492 between people with dyslexia and people who stutter.

493

494 Steven Frisson, PhD, is a lecturer in the Department of Psychology at the University of Birmingham. 495 His research includes the study of reading both in typical and atypical populations.

496

497 Linda Wheeldon, PhD, is a professor in the Department of Foreign Languages and Translation at 498 the Universitetet i Agder. Her research interests include the study of spoken language production, 499 reading, and bilingualism. 